\title{
Spawanie pojazdów szynowych - plany spawania
}

\section{Welding of rail vehicules - welding plans}

\section{Streszczenie}

Omówiono zasady tworzenia planów spawania przy budowie pojazdów szynowych. Przedstawiono wymagania normy EN 15085 w zakresie planów spawania. Wskazano zespoły pojazdów szynowych, dla których konieczne jest opracowanie planów spawania. Omówiono sposoby kwalifikowania instrukcji technologicznych, w zależności od klasy jakości spoiny. Podano reguły postępowania dotyczące ogólnych warunków spawania, w tym: kwalifikacji nadzoru spawalniczego, kwalifikacji spawaczy i operatorów/nastawiaczy, wymagań odnośnie stanowiska spawalniczego, czynności spawacza/operatora przed przystąpieniem do pracy, stanu materiałów podstawowych, dokumentów dostępnych na stanowisku, warunków przygotowania do spawania, zasad sczepiania, podgrzewania wstępnego i międzyściegowego, zasad stosowania płytek do- i wybiegowych, oceny materiałów dodatkowych do spawania, cięcia termicznego, wykonywania zakończeń spoin i napraw złączy spawanych. Przedstawiono też plan spawania zespołu podwozia pojazdu szynowego.

\section{Abstract}

There were the rules of composing welding plans at construction of rail-vehicules. EN 15085 requirements were presented. The sets of rail-vehicules for which the welding plans are necessary to be done were pointed out. The methods of WPS qualification were described, depending on the joint quality level. What is more, welding conditions rules were described (these are as follows: welding inspection qualification, welders and operators' qualifications, requirements on welding stations, welder/ operators activities before work beginning, parent materials conditions, documents available at working station, joint preparation conditions, the rules of tacking, preheating and interpass heating, the rules of using run-off and - run on plate, auxiliary materials and thermal cutting assessment, closing of the weld and joint repair work). The welding plan of rail-vehicule running gear was presented.

\section{Wstęp}

Zgodnie z normą EN 15085, przy budowie, przebudowie i naprawie pojazdów szynowych wytwórca powinien opracować spawalniczą dokumentację projektową.

W jej skład wchodzić mogą plany technologiczne, plany kolejności spawania, plany badań i instrukcje technologiczne spawania.

Posiadanie planów technologicznych konieczne jest dla następujących zespołów:

- wózków wagonowych (podzespoły, montaż),

- podwozia (z podzespołami),

- nadwozia (ściana boczna, ściana czołowa, dach),

Dr hab. inż. Jacek Słania, prof. IS- Politechnika Częstochowska, mgr inż. Henryk Fryc - ALSTOM - Konstal, Chorzów.
- innych elementów o wysokich wymaganiach pod względem bezpieczeństwa i funkcjonalności (np. takich jak wały przegubowe, belki hamulcowe, korpusy silników, belka skrętu, podpory czopa skrętu). Plany zawierające kolejność spawania wymagane są przy wykonywaniu kompleksowych zespołów, jak np.: - wózki wagonowe (belka bujakowa, belka skrętu łącznie z zespołem gniazda skrętu, ostojnica, czołownica, podpora gniazda skrętu, zawieszenie cięgieł, montaż ostojnicy i belki skrętu),

- podwozia wagonu (łącznie z belką skrętu, ostojnicą, czołownicą, podporą czopa skrętu, zawieszeniem cięgieł).

Norma EN 15085 dopuszcza stosowanie standardowych planów kolejności spawania (obowiązujących dla różnych typów pojazdów szynowych).

Jeżeli jest to konieczne, dodatkowa dokumentacja projektowa powinna być uzgodniona pomiędzy odpowiedzialnym nadzorem spawalniczym i klientem. 
Dodatkowa dokumentacja projektowa może obejmować m.in.:

- plany sczepiania,

- instrukcje napraw,

- plany badań,

- dokumentację dotyczącą oprzyrządowania i narzędzi,

- plany separacji uszkodzonych elementów konstrukcyjnych,

- wskazówki dotyczące przepisów BHP.

Instrukcje technologiczne spawania (wg EN ISO 15609-1 do EN ISO 15609-5, EN ISO 14555, EN ISO 15620) sa wymagane dla klasy jakości spoin $C P A$, CP B, CP C1, CP C2 i CP C3. Jeżeli wymaga tego klient, to instrukcje technologiczne są również wymagane dla klasy jakości spoiny CP D.

Sposoby kwalifikowania instrukcji technologicznych, w zależności od klasy jakości spoiny, są następujące:

- klasa jakości spoiny CP A - kwalifikowanie wg jednej z następujących norm: EN ISO 15614 lub EN ISO 15620; EN ISO 15613, ale tylko, jeśli przedłożono WPQR wg EN ISO 15614; dla materiałów o $R_{\text {eh }}>$ $500 \mathrm{MPa}$ lub zmechanizowanych procesów spawania obowiązuje EN ISO 15614, dla WPQR muszą być spełnione kryteria akceptacji dla tej klasy spoiny;

- klasa jakości spoiny CP B, CP C1, CP C2 - kwalifikowanie wg jednej $\mathrm{z}$ następujących norm: EN ISO 15613, EN ISO 14555, EN ISO 15620; jeśli ze względu na element konstrukcyjny lub materiał jest to wymagane, to należy stosować EN ISO 15614;
- klasa jakości spoiny CP C3 - kwalifikowanie wg jednej z następujących norm: EN ISO 15610, EN ISO 15611, EN ISO 15612, EN ISO 15613, EN ISO 14555, EN ISO 15620; jeśli ze względu na element konstrukcyjny lub materiał jest to wymagane, to należy stosować EN ISO 15614;

- klasa jakości spoiny CP D - zgodnie z wymaganiami klienta.

Wszystkie WPS, oprócz klasy jakości spoiny CP D i jeśli nie wyspecyfikowano tego w umowie, muszą być objęte zakresem ważności WPQR.

Praktycznie, przestrzegając tych reguł, wytwórcy opracowują zazwyczaj własny sposób tworzenia dokumentacji, który pozwala uniknąć powielania informacji ogólnych w kolejnych dokumentach. Nowy dokument tworzony jest tylko dla nowego projektu i zawiera specyficzne informacje $z$ nim związane i niezbędne do jego wykonania.

W skład takiego systemu wchodzą dokumenty zawierające reguły postępowania dotyczące uwarunkowań ogólnych, zwłaszcza:

- ogólnych warunków spawania (m.in. kwalifikacji nadzoru spawalniczego, kwalifikacji spawaczy i operatorów/nastawiaczy, stanowisk spawalnicze, wykazu czynności spawacza/operatora przed przystąpieniem do pracy, stanu materiałów podstawowych, wykazu dokumentów na stanowisku, ogólnych warunków przygotowania do spawania, zasad sczepiania, podgrzewania wstępnego
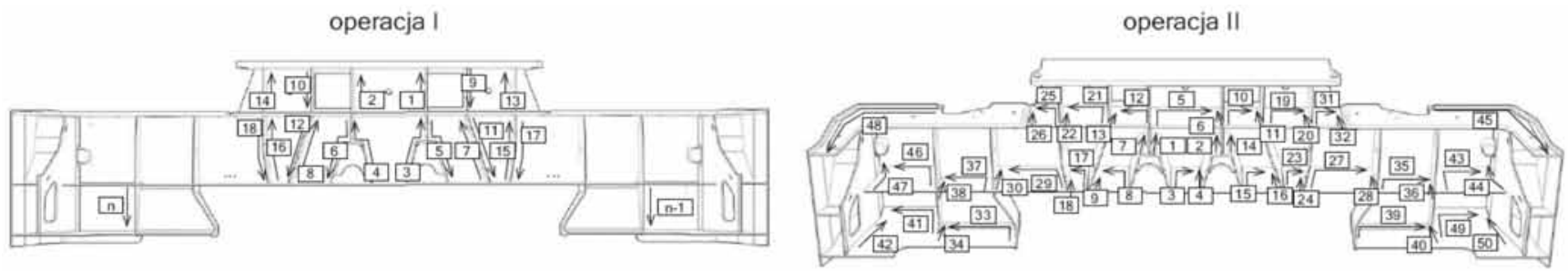

operacja III

operacja IV
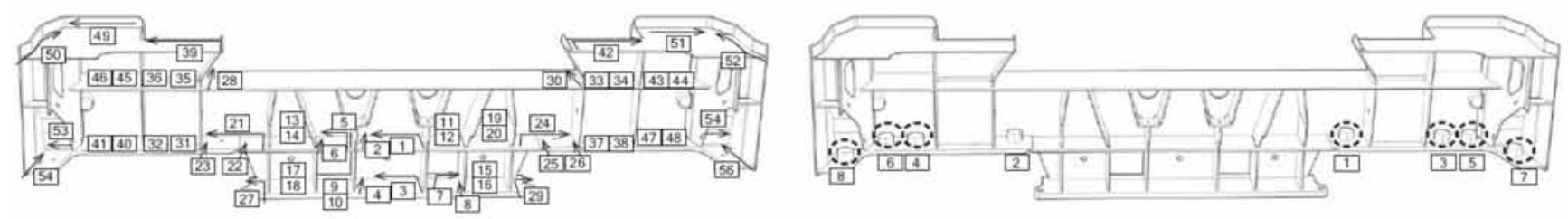

operacja V

operacja VI

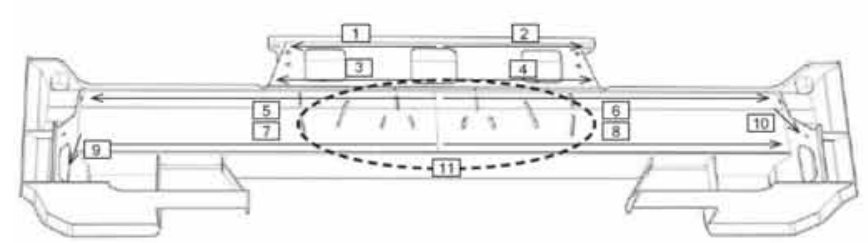

przestrzenie zamknięte
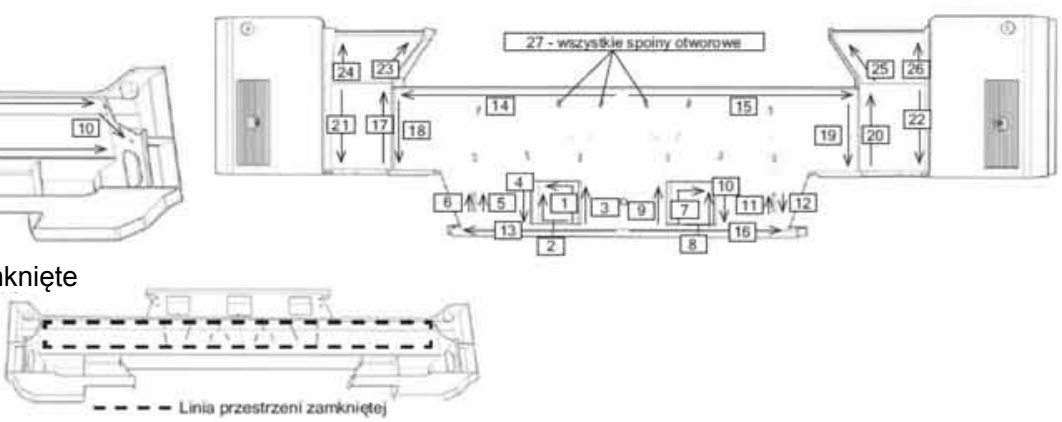

Rys. 1. Fragment planu spawania zawierający tylko kierunki i kolejność spawania

Fig. 1. Part of welding plan that contains only the directions and sequence of welding 

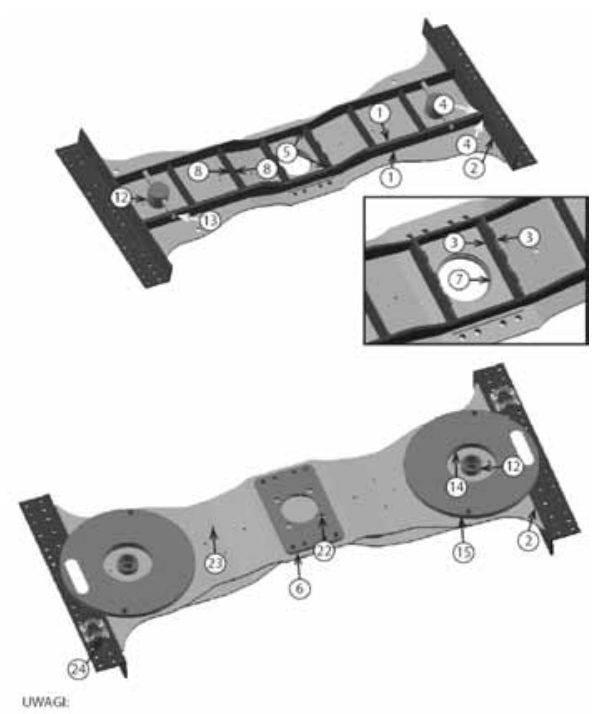

(1) - mumer spoiny

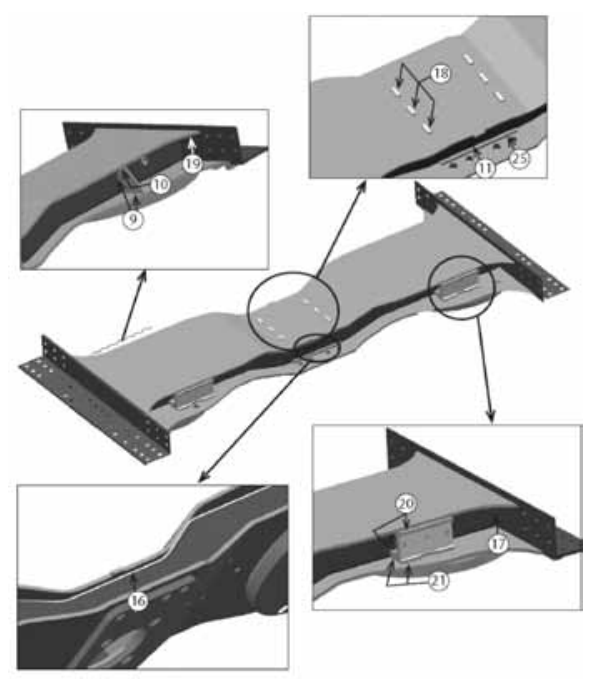

UNAG:

(1) - numer poiny
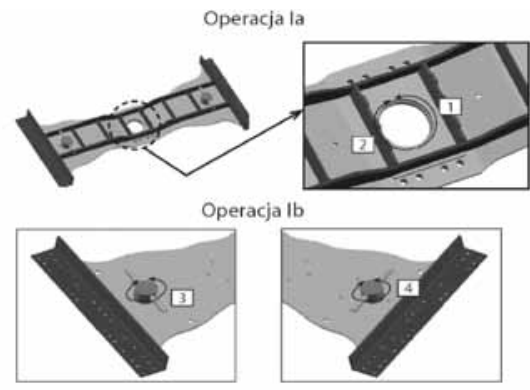

Operacja k

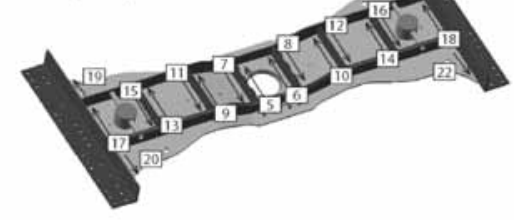

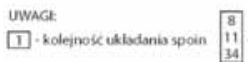
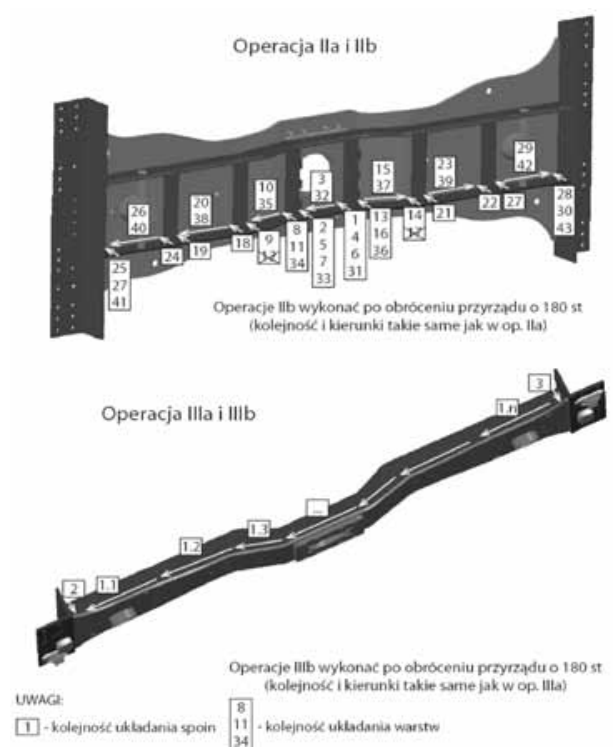
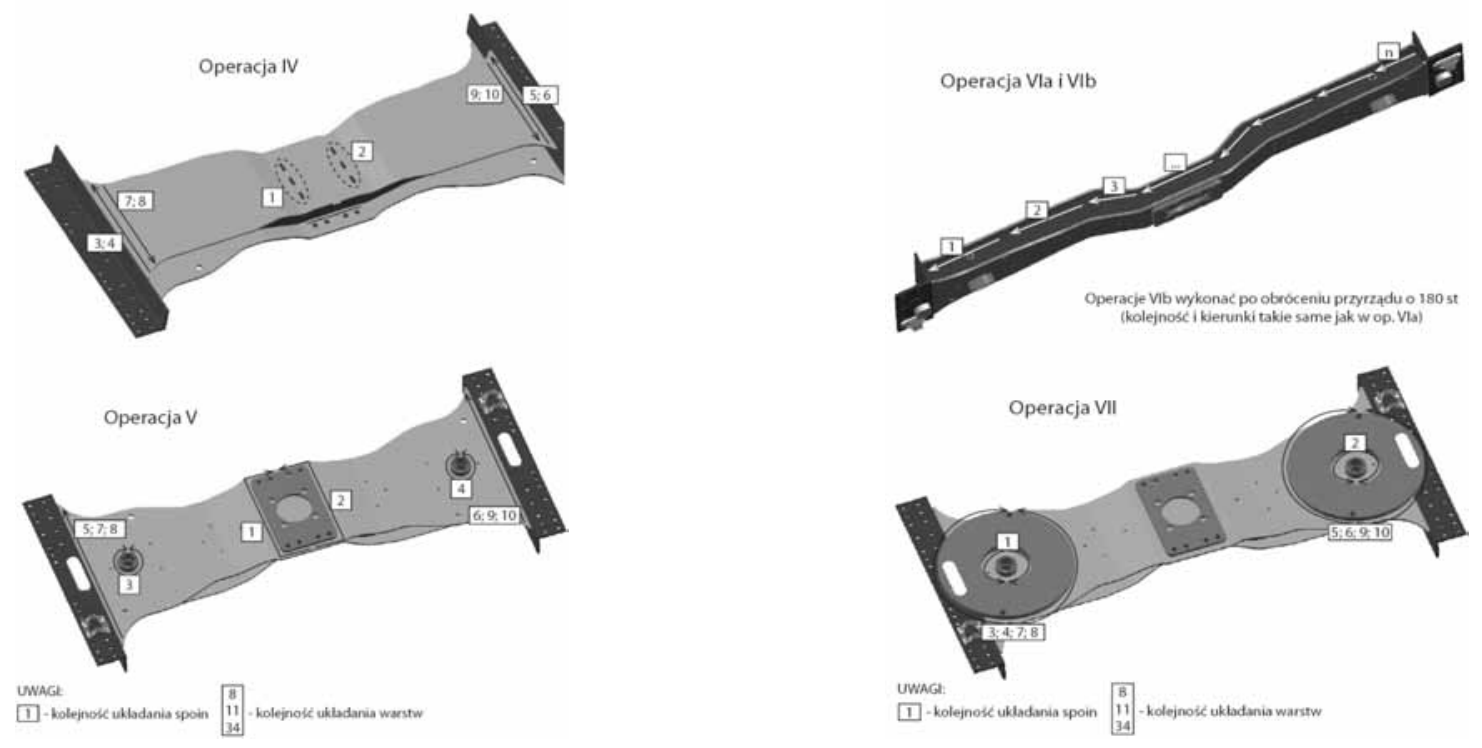

Rys. 2. Plan spawania zespołu podwozia pojazdu szynowego

Fig. 2. Welding plan of rail-vehicule running gear 
i międzyściegowego, zasad stosowania płytek doi wybiegowych, zajarzenia łuku, stosowanie środków przeciwodpryskowych, usuwania grani, przestrzenia zamknięta, znaku spawacza),

- zasad oceny materiałów dodatkowych do spawania (m.in. ustalenie zasad doboru spoiw wynikających z norm i przepisów związanych oraz nabytego doświadczenia, ustalenie sposobu badania poszczególnych partii drutów elektrodowych),

- cięcia termicznego (m.in. podanie ogólnych zasad cięcia w celu uniknięcia deformacji kształtu, zestawienie parametrów procesu dla posiadanych urządzeń i sprzętu, warunki BHP),

- ogólnych zasad wykonywania zakończeń spoin,

- zasad napraw złączy spawanych,

- sprawdzenia wyników spawania przez spawaczy i operatorów,

- zgrzewania łukowego kołków metalowych,

- prostowania termicznego konstrukcji po spawaniu. Plan spawania uwolniony od standardowych warunków zawiera zestawienie spoin z przyporządkowanymi WPS i/lub instrukcjami roboczymi, kierunki i kolejność wykonania poszczególnych spoin oraz informacje dodatkowe związane z danym zespołem.

Numeracja spoin może być wykonana w ramach dokumentacji rysunkowej lub być ujęta w planie spawania (rys. 1, 2).

Specyfika danego projektu może spowodować konieczność wykonania dodatkowych dokumentów zawierających szczegółowe warunki wykonania związane wyłącznie z tym projektem, np.:

- instrukcji montażu,

- instrukcji sczepiania, w której np. ustalone są miejsca ułożenia spoin sczepnych, obszary, które powinny być wolne od spoin sczepnych itp. (rys. 3),

- kwalifikacji spawaczy dla projektu (szczegółowe uprawnienia dla danego projektu z uwzględnieniem rodzaju zespołów i prób roboczych),

- instrukcji prostowania.

Niezależnie od planu spawania, dla każdego projektu zostaje opracowany plan kontroli i badań.

Zawiera on, w zakresie koniecznym, przyporządkowane do poszczególnych zespołów spawanych m.in.:

\section{Podsumowanie}

Plan spawania musi być nie tylko dostępny na stanowisku pracy, ale powinien być wykonany w sposób jak najbardziej czytelny dla spawacza.

Reguły wykonania, kryteria akceptacji itp. zawarte w normach i dokumentach związanych z wyrobem ułatwiają opracowanie dokumentów opisujących standardowe warunki wykonania, które wytwórca zapewnia.

Opisany system ogranicza do niezbędnego minimum ilość dokumentów do opracowania w przypadku nowych projektów. Oszczędzany jest cenny czas.
- zestawienie badań nieniszczących i niszczących,

- wykaz prób roboczych spawaczy,

- karty kontrolne,

- arkusze pomiarowe.

\section{Posługiwanie się planami spawania}

Plany spawania nie są tworzone dla nadzoru spawalniczego ani dla klienta. Tymi dokumentami musi umieć posługiwać się spawacz/operator. Dokument ten powinien być wykonany w sposób jak najbardziej czytelny dla spawacza, umożliwiając mu szybką lokalizację szukanej spoiny i przyporządkowanie jej np. WPS, wg którego ma ona zostać wykonana. Z praktyki wiadomo, że znajomość rysunku technicznego jest różna wśród spawaczy, dlatego wykorzystanie przy tworzeniu planów spawania np. rysunków aksonometrycznych jest dla nich dużym ułatwieniem.

Szkolenia w zakresie znajomości dokumentacji spawalniczej uzupełnione o szkolenia prowadzone bezpośrednio na stanowisku pracy powinny odbywać się cyklicznie.

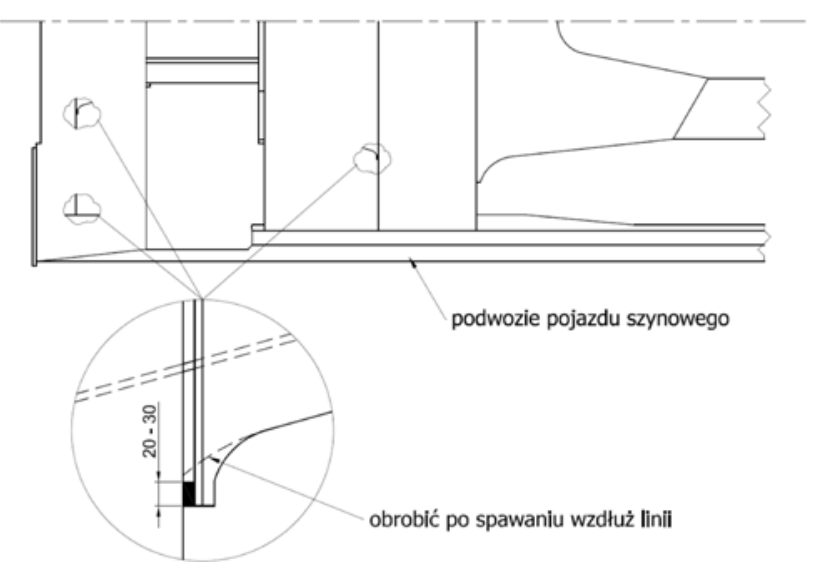

Rys. 3. Fragment planu sczepiania. Wyznaczenie położenia spoin sczepnych przy montażu pasów dolnych części czołowej podwozia Fig. 3. Part of tacking plan. Fixing position of tack weld at assembly of back belts of chassis frontal part

\section{Literatura}

[1] PN-EN 15085-2 Kolejnictwo. Spawanie pojazdów szynowych i ich części składowych. Część 2: Wymagania dotyczące jakości i certyfikacja zakładów spawalniczych.

[2] PN-EN 15085-3 Kolejnictwo. Spawanie pojazdów szynowych i ich części składowych. Część 3: Wymagania konstrukcyjne.

[3] PN-EN ISO 15614-1 Specyfikacja i kwalifikowanie technologii spawania metali. Badanie technologii spawania. Część 1: Spawanie łukowe i gazowe stali oraz spawanie łukowe niklu i stopów niklu. 